\title{
Overview of Constructions Made with architectural Membranes: Market, Geographical and Temporal Distribution
}

\author{
Mónica Macieira ${ }^{1,2, a}$, Paulo Mendonça ${ }^{1}$, and João Miranda Guedes ${ }^{2}$ \\ ${ }^{1}$ University of Minho, School of Architecture, Lab2PT, 4800-058 Guimarães, Portugal \\ ${ }^{2}$ University of Porto, Faculty of Civil Engineering, Construct, 4200-465 Porto, Portugal
}

\begin{abstract}
With the growing concern about material savings and climate change, it is important to analyse how membranes have been applied to constructions over time according to geographic location and type of use. There are many requirements associated with membrane building technologies and structures, though, currently, there is no membrane in the market that fully meets all requirements. In this way, the criteria to use architectural membranes must be weighted according to the intended application and location. Because of it, this research presents an overview on membrane constructions regarding their use and geographic related aspects, such as climate and risk vulnerability to natural disasters.
\end{abstract}

\section{Architectural membranes}

The term membrane is derived from the Latin word "membrane", meaning skin [1]. This term describes a flexible material, with reduced thickness relative to its surface area. When they have an architectural purpose, they are referred to architectural membranes (term used by Frei Otto, according to Glaeser [2]). They are fibrous or film materials, flexible, with reduced thickness and present stability only when submitted to tensile forces [3].

Architectural membranes can be simple or composite. The most common single membranes are polymer films and uncoated fabrics. Conventionally, composite architectural membranes consist of a fabric substrate and a polymeric coating. These layers are made of different materials and both are used to label the membrane material. The most common fabric and coating combinations are: polyester fabric coated with polyvinylchloride (PVC) or THV fluoropolymer; glass fibre fabric coated with polytetrafluoroethylene (PTFE) or silicone; and PTFE fabric coated with PTFE. The materials predominantly used in contemporary membrane structures are: glass fibre membrane coated with polytetrafluoroethylene (PTFE); polyester membrane coated with PVC and Ethylene Tetrafluoroethylene (ETFE) foil. These materials have a minimum B1 fire protection class (difficult to ignite) and have specific characteristics such as self-cleaning and high resistance to different weather conditions and ultra violet rays. According to Munter [4], a common property to all membrane materials is its reduced self-weight variable between 0.2 and $1.5 \mathrm{~kg} / \mathrm{m}^{2}$.

\footnotetext{
${ }^{\text {a }}$ Corresponding author: mrfmacieira@gmail.com
}

Woven fabrics, laminated fabrics and thin films are variants of the membrane concept. According Byrne [5], membranes belong to a group of materials called technical textiles, because they are within the engineering of flexible materials. Some authors, such as Byrne [5] and Krüger [6], among others, consider that even paper or polymeric films can be classified as textiles, because they have many similar properties, such as fibre manipulation and joining or finishing techniques. The use of textiles in construction is becoming increasingly common. According to Adanur [7], technical textiles, where architectural materials belong, are replacing traditional building materials such as metals, glass and others. Technical textiles are produced in industrialized countries and this involves various industry sectors and market segments. The characteristics of textiles and the potential applications in architecture are multiple. The main application category of technical textiles in architecture is denominated by Buildtech.

\section{Overview of architectural membranes material's market - Buildtech}

The Buildtech area (with 7\% market share - Figure 1a) is defined as a sub-sector of technical textiles. This area gathers all the developments and applications of membrane materials in civil construction. Architectural membranes, such as fiberglass, or polyester are widely applied in roofing to allow water vapor permeability and prevent moisture damages. Fiberglass or propylene nets are also used in the reinforcement and cracks repair in concrete and plaster elements. In Japan, carbon fibre is viewed with great interest as potential reinforcement 
material against seismic actions in buildings, although its cost is still a limiting factor in the diffusion of its application. Membrane materials are also applied in the course of building operations, such as safety nets, flexible concrete formworks, temporary site, acoustic/ dust barrier protections, etc.

Europe is one of the world's largest producers of technical textiles, accounting for a $24 \%$ share of the global market in terms of value [8]. Due to technological advances in the textile industry, with respect to equipment, machinery and raw materials used, it is estimated that the technical textiles market in Germany and France will grow at a much higher rate than other European countries [8]. The technical textiles are receiving significant support from various governments, due to the increasing awareness of the benefits associated to their products [9]. The main consumption areas of technical textiles in Western Europe are as follows: transport (21\%), protection (20\%) and construction (16\%) (Figure $1 \mathrm{~b})$.

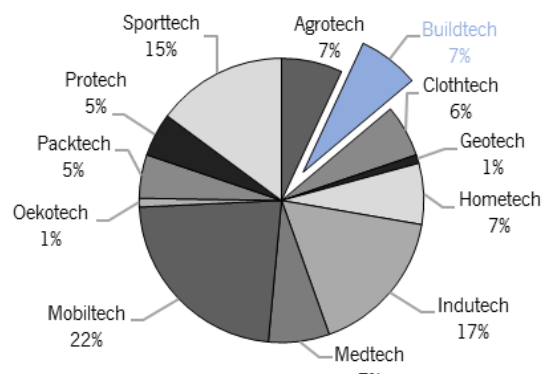

(a)

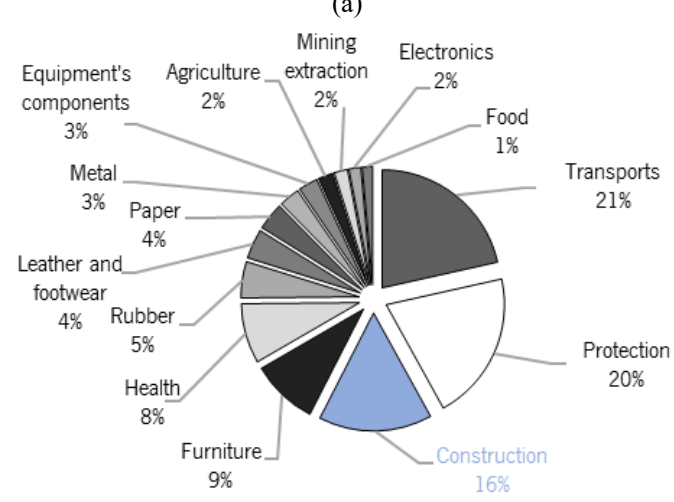

(b)

\begin{tabular}{|c|c|c|}
\hline Sub sector & Application area & Example of products \\
\hline Buildtech & $\begin{array}{l}\text { New constructions } \\
\text { and } \\
\text { rehabilitation/reno } \\
\text { vation. }\end{array}$ & $\begin{array}{l}\text { Membrane structures; reinforcing } \\
\text { materials; cables and ropes; roofs } \\
\text { and façade's underlining or } \\
\text { envelopes - vapour permeable } \\
\text { hydrophobic membranes; thermal } \\
\text { and acoustic insulation, coatings; } \\
\text { wallpapers; piping, water drainage } \\
\text { for foundations; formwork, soil } \\
\text { and vertical's elements } \\
\text { stabilization; protection against } \\
\text { different climatic conditions etc. }\end{array}$ \\
\hline
\end{tabular}

Figure 1. (a) Application areas of technical textile - sales ratio percentage at the global level [10]. (b) Consumption of technical textiles by application in Western Europe [9].

The European market for technical textiles, by application volume, is estimated at 9.95 million tonnes at a growing rate of $4.33 \%$ (CAGR) between 2015 and 2020. The Buildtech application sector was estimated at
0.58 million tonnes in 2015 and it is expected to reach a growth rate of $4.43 \%$ (CAGR) between 2015 and 2020 [8]. The strict safety and security standards in the European construction sector contribute to the growth of the European textile market.

\section{Overview of constructions with architectural membranes}

The membrane construction sector is highly specialized and involves different stakeholders - since architects, civil engineers, producers and manufacturing industries (from textile and polymers sectors) - which have built a dense network with metal and timber construction experts. Most of the companies involved are small or medium-sized enterprises, with the exception of companies supplying fabric's raw materials as well as those producing resins, coatings and chemical materials for finishes.

The possibilities of using membrane materials in the civil construction sector are almost unlimited. However, according to Ollenhauer [11], membrane producers find difficulties to implement these solutions. This is due to the strong cyclical nature of the construction industry, the long certification procedures and, above all, the dissemination/promotion for a diversified and highly fragmented group of professionals. Additionally, the difference in requirements, practices and constructive standards between countries makes it more difficult to enter this market.

The membranes have potential, but also limits of application in the construction sector. In some cases, the low durability of unprotected PVC membrane coatings and the fact that it is impossible to erect a membrane construction without the support of a rigid structure constitute some of the limitations. However, a membrane may result from the combination of different materials and achieve an "unlimited" duration [7].

Other functions, such as electrical conductivity, electroluminescence or the possibility to integrate nano structures, are relevant, as they positively alter the functional properties of the membrane. Here, the building envelope properties can be specifically adapted to change the environmental parameters - with positive contribution to ecological aspects - such as the reduction of required energy and resources, as well as the ability to reuse and recycle membrane materials and its related building components.

There are many requirements associated with membrane building technologies and structures though, currently, there are no membrane materials on the market that fully meet all requirements. In this way, the criteria must be weighted according to the intended application and location. For this, the next sections present an overview of membrane constructions regarding their use and geographical related aspects, such as climate and risk vulnerability to natural disasters. 


\subsection{Building's use type}

Architectural membranes are used in various ways in the buildings' construction - permanent or temporary. In a universe of 562 projects registered in the Tensinet database [12] (until 2015 year), 290 projects are permanent and 272 are temporary. Temporary structures, such as tents and awnings, are some of the applications with higher visibility of membranes' application. However, the architectural membranes' category has gained importance in the construction of semi-permanent structures, such as sports stadiums, exhibition centres and other large buildings. The analysis of Figure 2 shows that the most significant membrane's building use is for sports, followed by entertainment / leisure and exhibition functions. One of the common denominators to this type of buildings is having large spans.

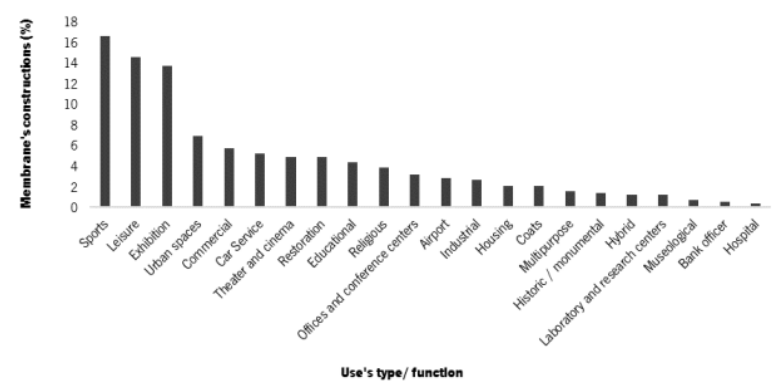

Figure 2. Percentage of membrane constructions identified in the Tensinet database [12] distributed by type/ function.

\subsection{Time period and geographic location}

The graph presented in Figure 3 was elaborated based on Ollenhauer's study [11]. It shows that: (1) the majority of companies that are currently leaders in the production of membranes began their activity between 1951 to 2000; (2) $63 \%$ of these companies are located in Europe, especially at Germany and at the Middle East countries, with an average age of 64 years. Existing companies with more than a century, in the production of membranes or in raw materials required for their production, are entirely located in Europe - representing $18 \%$ of existing companies. Companies created from 2001 till 2015 are located in Asia.
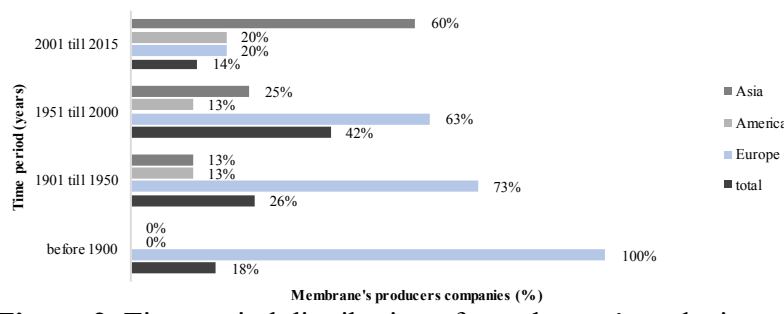

- total

Figure 2. Time period distribution of membranes' producing companies for the construction sector.

The following analysis was based on a sample of 562 case studies (constructed between 1960 and 2010), corresponding to all registered projects at Tensinet database [12] until 2015.
The graphic in Figure 4 shows that most of the identified membrane constructions were built between 1991 and 2000. Between the 80s and 90s there was an exponential increase of this type of construction that coincides with the development of high-performance fibres. However, there is a decrease in membrane constructions in the period between 2001 and 2010.

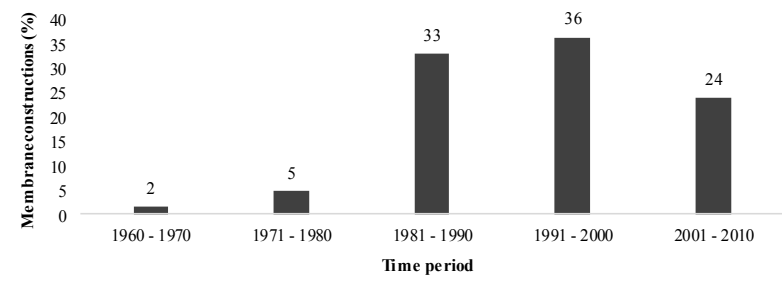

Figure 4. Percentage of membrane constructions identified in the Tensinet database [12] distributed by time periods.

Regarding the geographical distribution of these case studies, Europe has more than $50 \%$ of the worldwide membrane constructions (Figure 5).

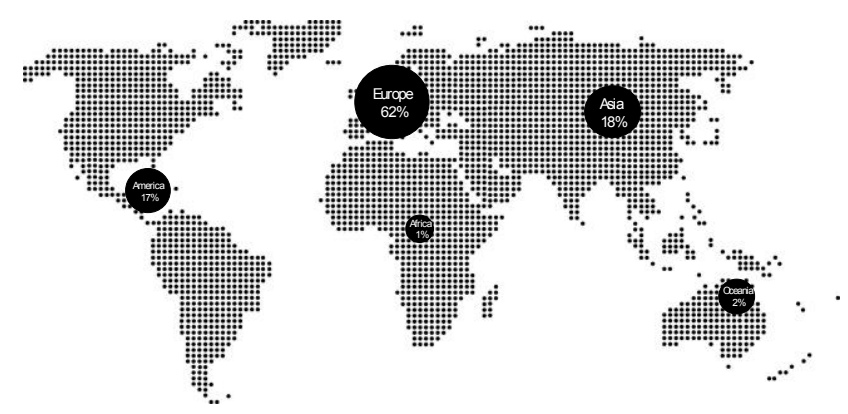

Figure 3. Geographical distribution of the membrane constructions identified in Tensinet database [12] by percentage.

\subsubsection{Climate zones}

The analysis of Figure 6 shows that more than half of membrane constructions are located in temperate climates, according to the classification of Koppen: tropical climate - hot and dry all year; arid climate - dry and hot all year round; Mediterranean climate - mild winter and warm and dry summer; temperate climate cold winter and mild summer; cold climate - cold all year and polar climate - very cold and dry all year round. The arid climate has the lowest percentage of membrane constructions and the records on cold and polar climates are not very expressive, not being represented in Figure 6. 


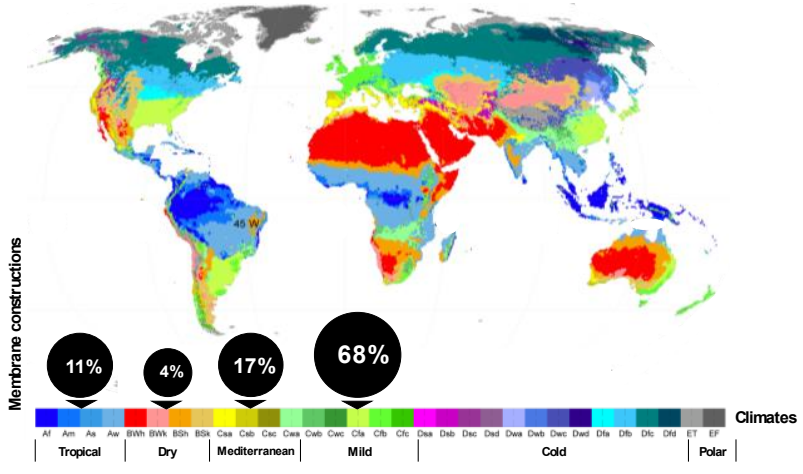

Figure 4. Infographic elaborated through the cross between Haschen's world map [13] and the percentage of membrane constructions (identified in the Tensinet database [15]) by climatic zone (according to the Koppen classification, for 1901 till 2010 time period).

Membrane synthetic materials have become highly efficient and offer the following advantages over conventional materials: enormous structural potential; resistance to severe climates; low thermal conductivity; versatility in terms of form and translucency; adjustable properties through additives; integration of functional and building components; flexibility, light control, thermal regulation, low environmental impact, elasticity, colour, resistance to chemicals and fungi, easy assembly, maintenance, etc. On the other hand, membrane materials, when combined or linked to conventional materials, such as glass, wood or metals, result in interesting constructive solutions - especially for the buildings' rehabilitation [14].

In order to overcome the thermal performance limitations of membranes, new developments, such as low-emissivity coatings for membranes, allow membrane-constructional solutions to assume more functions in the exterior buildings' envelope. Aerogels, and possibly phase change materials, are, in principle, suitable for improving multilayer membrane structures making them multi-purpose components, assuming advanced functions with respect to thermal insulation. Moreover, according to Cremers \& Laush [15], in the near future it will be possible to integrate layers of water and air in multilayer structures to increase thermal mass.

Due to the improved characteristics of membrane materials - in terms of the strength-to-weight ratio, durability, flexibility, insulation, acoustic properties, fire resistance - these can replace conventional building materials such as steel and other metals, wood and plastics. According to Grabe [16], examples of such innovative membrane's applications, as structural materials, now and in the future, include: (1) membrane coatings; (2) fibre-reinforced concrete and formwork with membranes for the execution of free forms; (3) erosion and landslide protection systems; (4) reinforcement of dikes and other water management systems; (5) light emission through optical fibre, flexible and durable pipes; (6) artificial islands and floating platforms.
The overlap of Figure 5 with 7 and 8 shows that most of membrane constructions are geographically located in areas of reduced, or very reduced risk to natural disasters. However, Table 3 shows that the second country with the highest percentage of membrane constructions Japan - has a very high level of risk to natural disasters. The Japanese islands are geographically located in areas subject to several severe natural hazards. Not only earthquakes, but also heavy snowfall and typhoons periodically affect buildings in Japan. Many membrane constructions have already experienced these disasters.

Kawaguchi [17] points out that, due to the extreme lightness of the membrane constructions, they are hardly affected by loads resulting from seismic events. On the other hand, from the observations and records made by Kawaguchi, it is concluded that the wind or strong snow directly affect the large spans of membrane constructions; some were damaged during strong typhoons and by snow overload, leading to the collapse of many roofs, including those of membrane. However, Kawaguchi's [17] observations also indicate that, compared to conventional materials, the early failure of membranes may have contributed to the protection of the support structure from more severe damage. The role of membrane as a force limiter must be recognized and can be considered as a positive element in the building design phase [17]. This is one of the membrane's potential, as it contributes to the building's structural durability and mitigate the risk to the building's occupants.

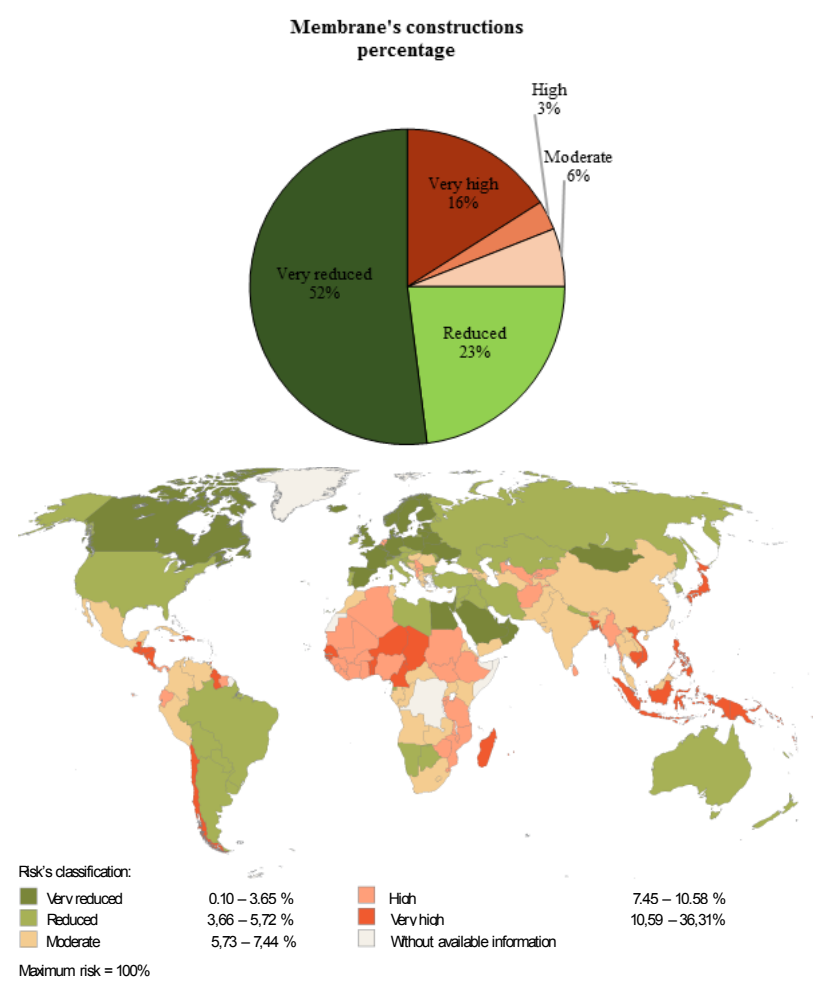

Figure 5. Map with worldwide distribution of the risk of exposure to natural disasters. Classification according to the quantile method [18]. Graph with percentage of analysed membrane constructions, according to their location in areas at risk of natural disasters.

\subsubsection{Vulnerability areas to natural disasters}


By comparing the geographic location of the analysed case studies and the risk index to the natural disaster, it was possible to determine the predominance of membrane constructions in locations with different natural disaster risk indexes. Table 1 shows that in the locations with higher risk there is also a higher predominance of membrane construction.

Table 1. Ranking of 30 countries, by increasing order of membrane constructions, and the respective risk index to natural disaster.

\begin{tabular}{|c|c|c|c|}
\hline Position & Location & $\begin{array}{c}\% \text { of membrane's } \\
\text { construction worldwide } \\
(1960-2010)\end{array}$ & $\begin{array}{l}\text { \% Natural disaster } \\
\text { risk index }[18]\end{array}$ \\
\hline 1 & Germany & 20,37 & 3,24 \\
\hline Position & Location & $\begin{array}{c}\% \text { of membrane's } \\
\text { construction worldwide } \\
(1960-2010)\end{array}$ & $\begin{array}{l}\text { \% Natural disaster } \\
\text { risk index [18] }\end{array}$ \\
\hline 2 & Japan & 8,01 & 14,10 \\
\hline 3 & France & 7,68 & 2,79 \\
\hline 4 & USA & 7,51 & 3,99 \\
\hline 5 & UK & 7,18 & 3,71 \\
\hline 6 & Spain & 7,01 & 3,38 \\
\hline 7 & Guatemala & 5,51 & 20,88 \\
\hline 8 & Belgium & 4,67 & 3,42 \\
\hline 9 & Italy & 4,34 & 4,88 \\
\hline 10 & Turkey & 3,34 & 5,52 \\
\hline 11 & Saudi Arabia & 3,17 & 1,32 \\
\hline 12 & Netherlands & 2,67 & 8,76 \\
\hline 13 & Australia & 1,67 & 4,51 \\
\hline 14 & Switzerland & 1,50 & 2,61 \\
\hline 15 & Austria & 1,34 & 3,80 \\
\hline 16 & Greece & 1,34 & 7,60 \\
\hline 17 & Uruguay & 1,34 & 4,09 \\
\hline 18 & China & 1,17 & 6,91 \\
\hline 19 & Canada & 0,83 & 3,18 \\
\hline 20 & Luxembourg & 0,83 & 2,68 \\
\hline 21 & Turkmenistan & 0,67 & 6,57 \\
\hline 22 & Chile & 0,50 & 12,28 \\
\hline 23 & Mexico & 0,50 & 6,39 \\
\hline 24 & Poland & 0,50 & 3,46 \\
\hline 25 & South Africa & 0,50 & 5,80 \\
\hline 26 & Brazil & 0,33 & 4,26 \\
\hline 27 & Portugal & 0,33 & 3,80 \\
\hline 28 & India & 0,33 & 7,17 \\
\hline 29 & Israel & 0,33 & 2,49 \\
\hline 30 & South Korea & 0,33 & 4,94 \\
\hline
\end{tabular}

\section{Conclusions}

This research presents an overview of the membrane market in the building construction sector. The confrontation between membranes' producing companies and membrane constructions shows that the majority of these construction were built in the time period in which there was the greatest growth of membranes' producing companies. That is, the construction market has accompanied the production market of these materials with little time lag between the production and application of these products. In other words, the innovation in this field quickly reaches the building market. Finally, this research points out that the membranes market has great potential to adapt to current and future challenges and trends.

\section{References}

1. T. Faegre, Tents, architecture of the nomads, edited by John Murray, London, England (1979).
2. L. Glaeser, The work of Frei Otto and his team 1955-1076, edited by Institute of Lightweight Structures, Germany (1978).

3. M. Milwich, Types and production of textiles used for building and construction, in "Textiles, Polymers and composites for Buildings", edited by G. Pohl, Woodhead Publishing limited in association with The Institute of textile, Cambridge, England, pp. 14-23 (2010).

4. M. Munter, Lightweight envelopes for old buildings: textiles membranes offer new opportunities for the energy-based refurbishments of existing buildings. Projektinfo 08/2012, Detailed information on energy research. BINE information services. Information on: http://www.bine.info/en/publications/publikation/lei chte-huellen-fuer-alte-

gebaeude/primaerenergiebilanz/\#sthash.p0CUKuDs. dpuf. [02/12/2015] (2012).

5. C. Byrne, Technical textiles market - overview, in AR Horrocks \& SC Anand (eds), in "Handbook of Technical Textiles", e-book, Woodhead Publishing Limited, Cambridge, England (2000).

6. S. Krüger, Textile architecture, edited by Jovis Verlag, Berlin, Germany (2009).

7. S. Adanur, Handbook of Weaving, edited by Technomic Publishing Company Inc., Lancaster, Pennsylvania, USA (2001).

8. Markets \& Markets, Technical textile market global forecast to 2020. Report code: AD 1528 (2016).

9. Euratex, The Future is textiles! Strategic research agenda, edited by ETP - European Technology Platform for the Future of Textiles and Clothing. Belgium (2006).

10. J. Grebe, Technical Textiles, Prospects and Challenges, edited by Commerzbank, Corporate Sector Analysis Frankfurt, Germany (2015).

11. C. Ollenhauer, Textiles in Architecture: Materials suppliers for building and construction, first edition, edited by Geoff Fisher, Textile Media Services (2011).

12. Tensinet, Database. Information on: http://www.tensinet.com/database/projects/1.html. [30/11/2015] (2015).

13. Haschen, Köppen climate classification: as a diagnostic tool to quantify climate variation and change. Information on: http://hanschen.org/koppen/ [19/11/2015] (2015).

14. M. Macieira, P. Mendonça, J. M. Guedes, Architectural membranes on building's functional refurbishment. IOP Conference Series: Materials Science and Engineering, 264(1), 012005. https://doi.org/10.1088/1757-899X/264/1/012005 (2017).

15. J. Cremers, F. Laush, Translucent high-performance silica-aerogel insulation for membrane structures, edited by Detail 4:410-412 (2008). 
16. T. Grabe, Tents, Sails, and Shelter: Innovations in Textile Architecture, edited by Werner Lang, Aurora McClain, School of Architecture of University of Texas at Austin, pp.6. (2010).

17. K. Kawaguchi, Recent developments in architectural fabric structures in Japan, in "Fabric Structures in Architecture", edited by J. Lllorens, Woodhead Publishing Series in Textiles, volume 165, Elsevier, pp 687-725 (2015).

18. UNU (United Nations University): Our World at Risk: A Look at World Risk Report 2012. World Risk Index as the result of exposure and vulnerability. Information on: http://unu.edu/publications/articles/our-world-atrisk.html (2015). 